\title{
Circuit-based grounding electrode considering frequency dependence for different input current
}

\author{
Ruqayyah Othman, Zulkurnain Abdul-Malek \\ Institute of High Voltage and High Current (IVAT), School of Electrical Engineering, \\ Faculty of Electrical Engineering, Universiti Teknologi Malaysia, Malaysia
}

\begin{tabular}{l} 
Article Info \\
\hline Article history: \\
Received Feb 13, 2020 \\
Revised Apr 13, 2020 \\
Accepted Apr 29, 2020 \\
\hline Keywords: \\
Circuit-based \\
Frequency dependence of soil \\
Grounding \\
Relative permittivity \\
Resistivity
\end{tabular}

\begin{abstract}
This paper presents a simulation work of circuit-based grounding electrode considering frequency dependence of soil parameters for three input currents which are impulse, AC $50 \mathrm{~Hz}$, and DC. The circuit parameters were determined by using Dwight and Sunde equations where a single horizontal grounding electrode was considered. Scott model was used for the frequency dependent model, to determine the frequency dependent soil resistivity and relative permittivity. It is found that the voltage response of the impulse current was highly affected $(75.2 \%)$ by the frequency compared to the voltage response of $\mathrm{AC} 50 \mathrm{~Hz}$ and DC. The impulse current response also gave the lowest peak in the analysis by the influence of frequency which make it better compared to the two other inputs. Therefore, it can be concluded that the frequency dependent of soil parameters is crucial and need to be considered in the transient analysis for any kind of input current to obtain accurate results.
\end{abstract}

Copyright $(2020$ Institute of Advanced Engineering and Science. All rights reserved.

\section{Corresponding Author:}

Zulkurnain Abdul-Malek,

Institute of High Voltage and High Current,

Universiti Teknologi Malaysia,

81310 Johor Bahru, Johor, Malaysia.

Email: zulkurnain@utm.my

\section{INTRODUCTION}

Lightning Protection System (LPS) is one of the most important aspect to be considered in order to protect lives and electrical equipment from the high current of the lightning strikes, where grounding system need to be designed properly for the safety purposes [1-3]. The types of grounding system that are commonly used are horizontal electrode, vertical electrode, grounding grid, and ring electrode, where the purpose of these grounding electrode is to absorb the high current from the lightning strikes that dispersed into the ground[4-6]. Encouraged by the safety concerned, many researchers have come with the theoretical and mathematical approaches to improve the grounding system performance by using different modelling approaches. The most popular types of grounding system modelling are electromagnetic field model (EMF), transmission line model, hybrid model, and circuit-based model [7, 8]. Among these model, electromagnetic field model is known to be the most accurate model for the performance aspect, however the formulation and expression is complex since Maxwell equations is involved and is hard to compute [9-11]. In contrary, the circuit-based model is the easiest to compute and the expressions is simple, but it struggles from inaccuracy problem [12]. This work concerned is to improve the circuit-based model grounding electrode by considering the key parameters not previously considered.

Many studies have been done previously to improve the circuit-based model where some of the parameters have been considered, such as the integration of soil ionization effect, current rate of rise, mutual coupling, frequency influence, and others for all types of grounding electrode [13-23]. However, the study regarding the influence of frequency dependent of soil parameters is still not covered entirely since 
there is only one study for each horizontal and vertical grounding electrode, and under lightning current only for the input signal, and the results is not sufficient since it used the equivalent frequency [16-19]. Due to the lack of information regarding the issue, further improvement needs to be done to tackle the inaccuracy problem for circuit-based model. One of the rising issues is on the transient response in impulse current condition, where previous work stating that the performance of the response when injected with impulse and transient current gives different behavior, for the earthing system previously designed for a low voltage and low power frequency only [2, 7].

This work aims to develop an improved circuit-based model for grounding electrodes considering the effects of frequency dependent of soil resistivity and relative permittivity on grounding electrode impedance and voltage response, under several types of input current (impulse, AC and DC), and it is limited to a single horizontal grounding electrode. The calculation and simulation work are done in MATLAB and CDEGS software.

\section{RESEARCH METHOD}

\subsection{Circuit-based model parameters}

A lump circuit-based model which consist of $\mathrm{R}, \mathrm{L}$, and $\mathrm{C}$ is used in the transient analysis to represent the horizontal grounding electrode as shown in Figure 1. Figure 2 shows a representation of the horizontal grounding electrode injected at a point with a downlead, with radius, a, length, l, and depth, $\mathrm{d}$, buried in a uniform soil. As shown in (1) and (2) are given by Dwight and Sunde to determine the electrode resistance of the horizontal and vertical grounding electrode respectively.

$$
\begin{aligned}
& R=\frac{\rho}{\pi l}\left[\log \left(\frac{2 l}{\sqrt{2 a d}}\right)-1\right] \\
& R=\frac{\rho}{2 \pi l}\left[\log \left(\frac{4 l}{a}\right)-1\right]
\end{aligned}
$$

where $\rho$ is the soil resistivity (in ohm-meter), $l$ is the electrode length (in meter), and $a$ is the electrode radius (in meter). The inductance value is given by (3) which is,

$$
L=\frac{\mu l}{\pi}\left[\log \left(\frac{2 l}{\sqrt{2 a d}}\right)-1\right]
$$

where $d$ is the depth (in meter) of the electrode buried in the soil, and $\mu$ is the relative permeability given by $4 \pi \times 10^{-7}$. Conductance value can be found by using (4) which is,

$$
C=\frac{\rho \varepsilon}{R}
$$

where $\varepsilon$ is the soil relative permittivity (in Farad per meter).

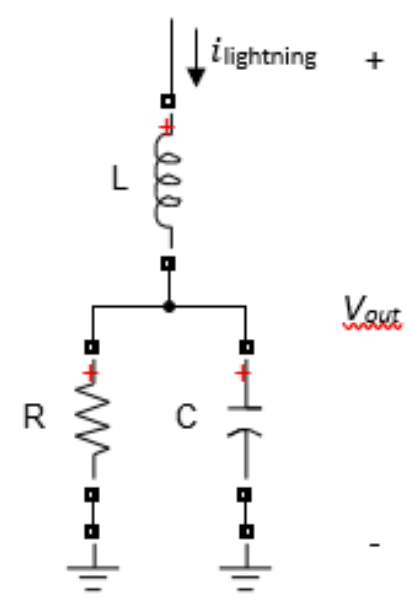

Figure 1. A lump circuit model of grounding electrode consisting resistor, inductor, and capacitor 


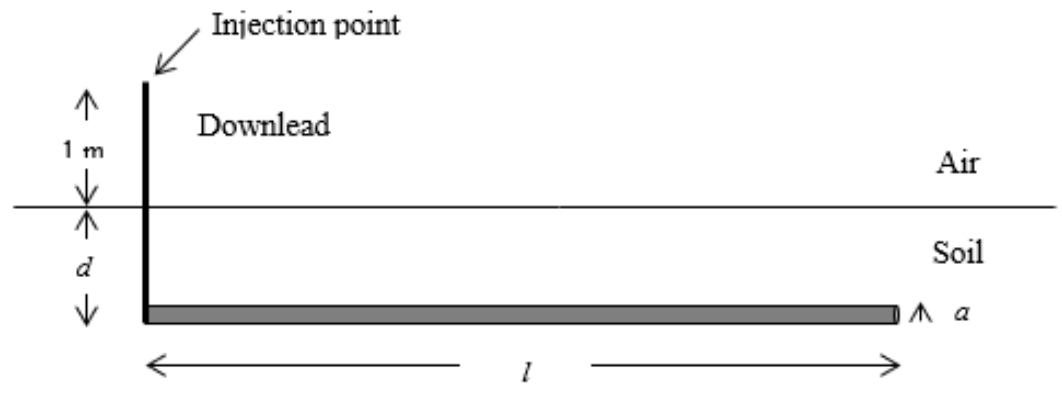

Figure 2. Representation of a single horizontal grounding electrode with radius $a$, length $l$, depth $d$, buried in uniform soil, injected at a point with a vertical downlead

\subsection{Frequency dependence of soil parameters}

Scott model is used in the analysis as the frequency dependence model due to its accuracy compared to other models based on the previous studies [16-20, 24, 25]. The expression of conductivity, $\sigma(f)$ and relative permittivity, $\varepsilon_{r}(f)$ as a function of frequency proposed by Scott are given by (5) and (6) respectively.

$$
\begin{aligned}
& \sigma(f)=0.028+1.098 \log _{10}\left(\sigma_{0}\right)-0.068 \log _{10}(f)+0.036 \log _{10^{2}}\left(\sigma_{0}\right)-0.046 \log _{10}(f) \log _{10}\left(\sigma_{0}\right)+ \\
& 0.018 \log _{10^{2}}(f) \\
& \varepsilon_{r}(f)=5.491+0.946 \log _{10}\left(\sigma_{0}\right)-1.097 \log _{10}(f)+0.069 \log _{10^{2}}\left(\sigma_{0}\right)-0.114 \log _{10}(f) \log _{10}\left(\sigma_{0}\right)+ \\
& 0.018 \log _{10^{2}}(f)
\end{aligned}
$$

where $\sigma_{0}$ is the conductivity at $100 \mathrm{~Hz}$ in $(\mathrm{mS} / \mathrm{m}), f$ is the frequency in Hertz $(\mathrm{Hz})$ and $\varepsilon_{r}$ is the soil permittivity $(\mathrm{F} / \mathrm{m})$. The overall computation process of the transient analysis is described in the flowchart in Figure 3. Firstly, the parameters of the circuit are determined by using (1), (3), and (4). Then, the frequency dependent circuit model is determined by using (5) and (6) as proposed by Scott. The frequency dependent circuit model is then computed by using CDEGS software (FFT-IFFT). The computation is repeated by changing the injected input current and the results obtained is compared.

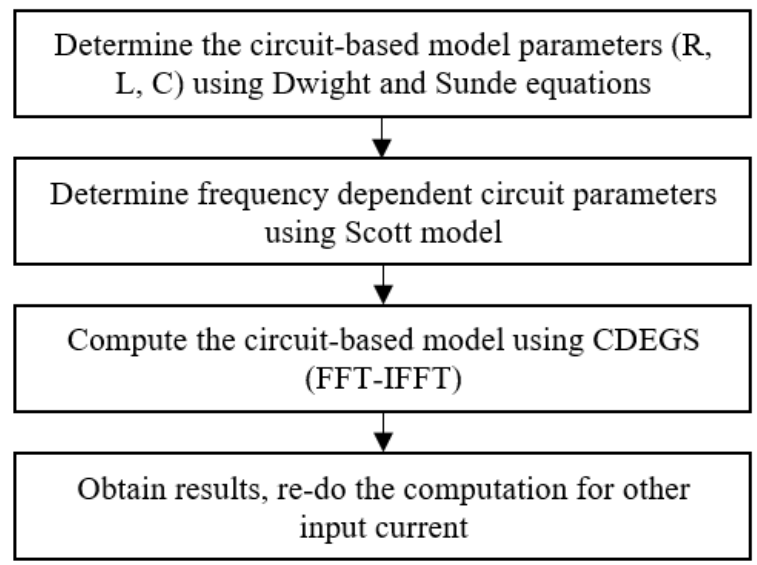

Figure 3. Flowchart of the computation process for the transient analysis

\section{RESULTS AND ANALYSIS}

A $15 \mathrm{~m}$ long vertical grounding electrode, with $0.02 \mathrm{~m}$ diameter, buried in $1 \mathrm{~m}$ depth of uniform soil is considered in this study. The soil relative permittivity is assumed to be constant which is 1 for the frequency independent analysis, and the soil resistivity is set to several different values $(100 \Omega \mathrm{m}, 500$ $\Omega \mathrm{m}, 1000 \Omega \mathrm{m}$, and $2000 \Omega \mathrm{m}$ ). The horizontal grounding electrode is injected at a point by a $10 \mathrm{kA}-$ peak input current with various shape; $1 / 35 \mu \mathrm{s}$ impulse, $50 \mathrm{~Hz}$ AC, DC. The expression of the double exponential current is given by $\mathrm{i}(\mathrm{t})=10.244\left(\mathrm{e}^{-2000 \mathrm{t}}-\mathrm{e}^{-5500000 t}\right) \mathrm{kA}$. 
Figure 4 and Figure 5 shows the peak voltages of frequency independent and frequency dependent model for three different input current which are impulse, AC and DC, and the results obtained is tabulated in Table 1. Voltage responses of the impulse current and AC $50 \mathrm{~Hz}$ for frequency independent model in Figure 4 seems to only have a slightly different (less than 4.7\%), but DC voltage response gives much lower value compared to the other two (34\% lower). DC does not affect by the frequency because it has no frequency element, so the response obtained is better than the impulse and AC $50 \mathrm{~Hz}$.

In Figure 5, for the frequency dependent model, it can be seen that the peak voltage response for impulse current gives a better result with the influence of frequency where it gives the lowest response, $48.4 \%$ lower than peak voltage of AC $50 \mathrm{~Hz}$ and $62.5 \%$ lower than peak voltage of DC input at the highest soil resistivity of $2000 \Omega \mathrm{m}$. As for the low resistivity $(100 \Omega \mathrm{m})$, the peak voltages of all the input current are not very much different. Based on the results obtained in Table 1, the peak voltage of the impulse current has the highest difference by comparing the frequency dependent and frequency independent model where the difference is $75.2 \%$, while AC $50 \mathrm{~Hz}$ has $49.5 \%$ and DC has none because DC has no frequency. It reveals that the response obtained by the impulse current is the most affected by frequency. As for the shape of the voltage response, it is accordingly to the input current shape for every response.

Table 1. Peak voltage for both frequency dependent and independent model when impulse, AC $50 \mathrm{~Hz}$, and DC injected at one end with varied soil resistivity

\begin{tabular}{ccccccc}
\hline \multirow{2}{*}{ Nominal Soil Resistivity $(\Omega \mathrm{m})$} & $\begin{array}{c}\mathrm{Vp}(\mathrm{kV}) \\
(1 / 35-\mu \mathrm{s})\end{array}$ & $\begin{array}{c}\mathrm{Vp}(\mathrm{f}) \mathrm{kV} \\
(1 / 35-\mu \mathrm{s})\end{array}$ & $\begin{array}{c}\mathrm{Vp}(\mathrm{kV}) \\
(\mathrm{AC})\end{array}$ & $\begin{array}{c}\mathrm{Vp}(\mathrm{f}) \mathrm{kV} \\
(\mathrm{AC})\end{array}$ & $\begin{array}{c}\mathrm{Vp}(\mathrm{kV}) \\
(\mathrm{DC})\end{array}$ & $\begin{array}{c}\mathrm{Vp}(\mathrm{f}) \mathrm{kV} \\
(\mathrm{DC})\end{array}$ \\
\hline 100 & 25.2 & 12.2 & 25.29 & 21.67 & 17.88 & 17.88 \\
500 & 132 & 45 & 126.63 & 85.22 & 89.42 & 89.42 \\
1000 & 264 & 77 & 254.21 & 149.89 & 178.82 & 178.82 \\
2000 & 540 & 134 & 514.46 & 259.71 & 357.65 & 357.65 \\
\hline
\end{tabular}

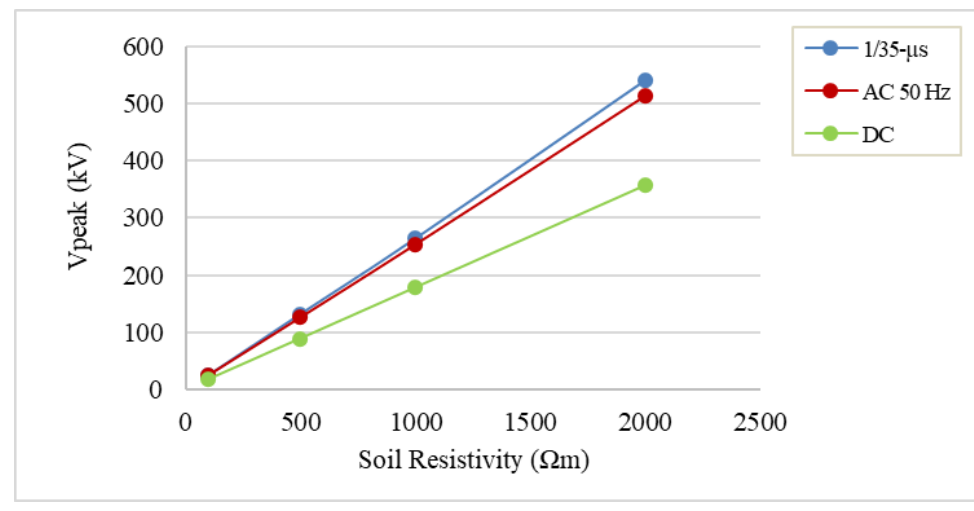

Figure 4. Effect of $10 \mathrm{kA}$-peak input current with various shape on the frequency independent electrode model peak voltage for varying soil resistivity; $1 / 35-\mu$ s impulse, AC $50 \mathrm{~Hz}$, DC

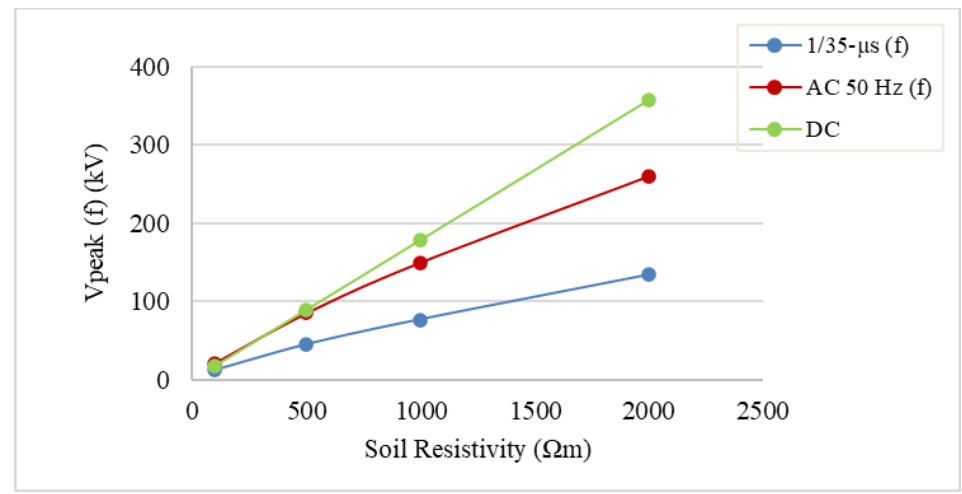

Figure 5. Effect of $10 \mathrm{kA}$-peak input current with various shape on the frequency dependent electrode model peak voltage for varying soil resistivity; $1 / 35-\mu$ s impulse, AC $50 \mathrm{~Hz}, \mathrm{DC}$ 
The results obtained somehow agrees with the previous work stating that the performance of the response when injected with impulse and transient current gives different behavior, for the earthing system previously designed for a low voltage and low power frequency only [2, 7]. Therefore, by considering the frequency in the transient analysis, more accurate results can be obtained especially for impulse current condition. The novelty of this work is by proofing that the impulse current experienced different behaviour in the transient response as stated in the previous work, where frequency need to be included in the analysis, which have been successfully achieved in this work by simulation and analysis.

\section{CONCLUSION}

The circuit-based model of grounding electrodes with frequency dependent of soil and three different input currents were successfully modelled. It is found that the voltage response of the impulse current is better with the influence of frequency and also the most affected by the frequency compared to the responses of $\mathrm{AC} 50 \mathrm{~Hz}$ and $\mathrm{DC}$ input. The study also concluded that considering the frequency dependence of soil parameters is crucial in the transient performance analysis to obtain accurate results.

\section{ACKNOWLEDGEMENTS}

The authors wish to thank the Ministry of Higher Education (MOHE) and Universiti Teknologi Malaysia (Research Vote Nos. 4F828 and 18H10) for the financial aid.

\section{REFERENCES}

[1] M. Akbari, et al, "The Effect of Frequency Dependence of Soil Electrical Parameters on the Lightning Performance of Grounding Systems," IEEE Transactions on Electromagnetic Compatibility, vol. 55, no. 4, pp. 739-746, 2013.

[2] O. Kherif, S. Chiheb, M. Teguar, A. Mekhaldi, and N. Harid, "Time-domain modeling of grounding systems' impulse response incorporating nonlinear and frequency-dependent aspects," IEEE Transactions on Electromagnetic Compatibility, vol. 60, no. 4, pp. 907-916, 2017.

[3] D. S. Gazzana, A. S. Bretas, G. A. D. Dias, M. Tello, D. W. P. Thomas, and C. Christopoulos, "The transmission line modeling method to represent the soil ionization phenomenon in grounding systems," IEEE Transactions on Magnetics, vol. 50, no. 2, pp. 505-508, 2014.

[4] L. Grcev, "Time-and frequency-dependent lightning surge characteristics of grounding electrodes," IEEE Transactions on Power Delivery, vol. 24, no. 4, pp. 2186-2196, 2009.

[5] H. Hasan, et al, "Characterization of horizontal earth electrodes: variable frequency and impulse responses," 2015 50th International Universities Power Engineering Conference (UPEC), pp. 1-5, 2015.

[6] M. Mokhtari and G. B. Gharehpetian, "Integration of energy balance of soil ionization in cigre grounding electrode resistance model," IEEE Transactions on Electromagnetic Compatibility, vol. 60, no.2, pp. 402-413, 2017.

[7] R. Alipio and S. Visacro, "Impulse efficiency of grounding electrodes: Effect of frequency-dependent soil parameters," IEEE Transactions on Power Delivery, vol. 29, no. 2, pp. 716-723, 2014.

[8] B. Z. JinpengWu, et al, "A comprehensive approach for transient performance of grounding system in the time domain," IEEE Transactions on Electromagnetic Compatibility, vol. 57, no. 2, pp. 250-256, 2015.

[9] J. L. G. L. A. Salgado, J. Torres, E. O. Hernández, "Transient analysis of grounding systems under lightning strikes considering soil ionization," 2010 IEEE Industry Applications Society Annual Meeting, pp. 1-7, 2010.

[10] S. Yuda, S. Sawaki, Y. Baba, N. Nagaoka, and A. Ametani, "Application of the TLM method to transient simulations of a conductor system with a lossy ground: Grounding electrodes and an overhead wire," IEEE Transactions on Electromagnetic Compatibility, vol. 55, no. 1, pp. 175-182, 2012.

[11] B. Z. linliang He, "Soil Ionization phenomenon around grounding electrode under lightning impulse," 2013 AsiaPacific Symposium on Electromagnetic Compatibility (APEMC), pp. 1-5, 2013.

[12] R. G. Olsen and L. Grcev, "Analysis of high-frequency grounds: comparison of theory and experiment," IEEE Transactions on Industry Applications, vol. 51, no. 6, pp. 4889-4899, 2015.

[13] M. Mokhtari, et al, "An improved circuit-based model of a grounding electrode by considering the current rate of rise and soil ionization factors," IEEE Transactions on Power Delivery, vol. 30, no. 1, pp. 211-219, 2015.

[14] M. M. R. Araneo, S. Lauria, A. Geri, F. Gatta, S. Celozzi, "Hybrid and pi-circuit approaches for grounding system lightning response," 2015 IEEE Eindhoven PowerTech, pp. 1-6, 2015.

[15] F. H. S. Idir Djamel, Semaan Georges, "Transient response of grounding systems under impulse lightning current," 2016 Electric Power Quality and Supply Reliability (PQ), pp. 71-75, 2016.

[16] M. Mokhtari, Z. Abdul-Malek, and C. L. Wooi, "Integration of frequency dependent soil electrical properties in grounding electrode circuit model," International Journal of Electrical and Computer Engineering (IJECE), vol. 6, no. 2, pp. 792-799, 2016.

[17] P. Yutthagowith, "A modified pi-shaped circuit-based model of grounding electrodes," 2016 33rd International Conference on Lightning Protection (ICLP), pp. 1-4, 2016.

[18] R. Othman and Z. Abdul-Malek, "An improved circuit-based grounding electrode considering frequency dependence of soil parameters," 2018 International Conference on Electrical Engineering and Computer Science (ICECOS), pp. 271-274, 2018. 
[19] R. Othman, Abdul-Malek, Z., Jambak, M. I., Nawawi, Z., \& Sidik, M. A. B., "Circuit-based model grounding electrode considering frequency dependent of soil resistivity and relative permittivity," in Advances in Electronics Engineering, pp. 87-92, 2020.

[20] D. Cavka, N. Mora, and F. Rachidi, "A comparison of frequency-dependent soil models: application to the analysis of grounding systems," IEEE Transactions on Electromagnetic Compatibility, vol. 56, no. 1, pp. 177-187, 2013.

[21] M. Mokhtari, Z. Abdul-Malek, and Z. Salam, "The effect of soil ionization on transient grounding electrode resistance in non-homogeneous soil conditions," International Transactions on Electrical Energy Systems, vol. 26, no. 7, pp. 1462-1475, 2016.

[22] M. Mokhtari, Z. Abdul-Malek, and G. B. Gharehpetian, "A critical review on soil ionisation modelling for grounding electrodes," Archives of Electrical Engineering, vol. 65, no. 3, pp. 449-461, 2016.

[23] E. P. Nicolopoulou, F. E. Asimakopoulou, I. F. Gonos, and I. A. Stathopulos, "Comparison of equivalent circuit models for the simulation of soil ionization," Electric Power Systems Research, vol. 113, pp. 180-187, 2014.

[24] M. Mokhtari, Z. Abdul-Malek, and G. B. Gharehpetian, "A new soil ionization model for grounding electrodes," International Transactions on Electrical Energy Systems, vol. 27, no. 3, pp. e2266, 2017.

[25] N. M. Damir Cavka, et al, "On the application of frequency dependent soil models to the transient analysis of grounding electrodes," 2013 International Symposium on Electromagnetic Compatibility, pp. 777-781, 2013.

\section{BIOGRAPHIES OF AUTHORS}

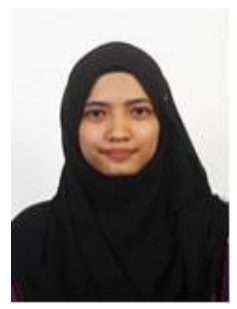

R. Othman received the Diploma in Electronic Engineering in 2013 and B.E. degree in electrical engineering in 2016 from Universiti Teknologi Malaysia (UTM), and currently persuing M.Phil in electrical engineering at Institute of High Voltage and High Current (IVAT), Universiti Teknologi Malaysia. Her research interest includes the high voltage engineering and transient simulation on grounding systems with frequency influence.

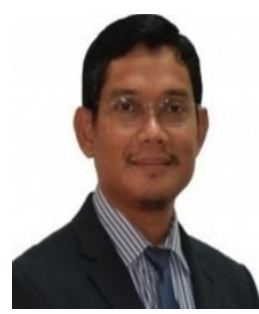

Z. Abdul-Malek received the B.E. degree in electrical and computer systems from Monash University, Melbourne, Australia, in 1989, the M.Sc. degree in electrical and electromagnetic engineering with industrial applications from the University of Wales Cardiff, Cardiff, U.K., in 1995 and the Ph.D. degree in high voltage engineering from Cardiff University, Cardiff, U.K., in 1999.He was a Lecturer with Universiti Teknologi Malaysia (UTM) for 29 years, where he is currently a Professor of High Voltage Engineering with the Faculty of Electrical Engineering. $\mathrm{He}$ is currently the Director of the Institute of High Voltage and High Current (IVAT), UTM. He has published two books and has authored and co-authored more than 100 papers in various technical journals and conference proceedings. His research interests include high-voltage instrumentation, lightning protection, detection and warning systems, partial discharges, nanodielectrics, and condition monitoring of power equipments. Professor Abdul-Malek is actively involved in many national committees. He is the Chairman, Working Group on HighVoltage and High-Current Test Techniques. He is also a member of IEC Certification Body Management Committee, Technical Committee on High Voltage Power Transmission, Working Group on High Voltage Switchgear and Controlgears, Technical Working Group for ElectricalTesting, and Department of Standards IEC 17025 Technical Assessors. He is amember of the Power and Energy Society, Dielectrics and Electrical Insulation Society, and CIGRE. 